\title{
Análise do desempenho produtivo e das características físico-mecânicas dos couros de tilápias do Nilo alimentadas com diferentes níveis de própolis nas rações
}

Analysis of the productive performance and physical-mechanical characteristics of Nile tilapia

leathers fed with different levels of propolis in the rations

Análisis del comportamiento productivo y características físico-mecánicas de cueros de tilapia del

Nilo alimentados con diferentes niveles de propóleo en las raciones

Gislaine Gonçalves Oliveira ORCID: https://orcid.org/0000-0002-7819-3493 Universidade Estadual de Maringá, Brasil E-mail: gislaine_oliveira14@hotmail.com

Rafael Seki Kiohimo

ORCID: https://orcid.org/0000-0002-1882-8995 Universidade Estadual de Maringá, Brasil E-mail:rafaelseki@outlook.com

Lucimar Pontara Peres ORCID: https://orcid.org/0000-0003-2563-3114 Universidade Estadual de Maringá, Brasil E-mail: lppmoura@uem.br

Carla Cristina Alves Nogueira ORCID: https://orcid.org/0000-0002-2123-4717

Universidade Estadual de Maringá, Brasil E-mail: carlacristina18_@outlook.com

Sabrina Campos Sbaraini ORCID: https://orcid.org/0000-0002-7165-6563 Universidade Estadual de Maringá, Brasil Email:sabrinacsbaraini@gmail.com

Sabrina Martins dos Santos ORCID: https://orcid.org/0000-0002-6658-688X Universidade Estadual de Maringá, Brasil E-mail: sabrina.martins.dos.santos@hotmail.com

Adriana Ferreira da Silva ORCID: https://orcid.org/0000-0002-6615-7938

Universidad Autónoma de Yucatán, México E-mailadriana.dasilva@correo.uady.mx:

Melina Franco Coradini ORCID: https://orcid.org/0000-0001-7351-0237 Universidade Estadual de Maringá, Brasil E-mail:melinacoradini@gmail.com

Jaisa Casetta

ORCID: https://orcid.org/0000-0001-9994-077X

Universidade Estadual de Maringá, Brasil

E-mail: jaisacasettta@hotmail.com

Marcos Antonio Matiucci

ORCID: https://orcid.org/0000-0003-2053-2672

Universidade Estadual de Maringá, Brasil

E-mail:m.matiucci@hotmail.com

Carolina Schlotefeldt

ORCID: https://orcid.org/0000-0002-4126-8068

Universidade Estadual de Maringá, Brasil

E-mail: carolinaschlotefeldt@gmail.com

Andresa Carla Feihrmann

ORCID: https://orcid.org/0000-0003-2389-0467

Universidade Estadual de Maringá, Brasil E-mail: andresafeihrmann@gmail.com

Nilton Marengoni

ORCID: https://orcid.org/0000-0002-0666-4567

Universidade Estadual do Oeste do Paraná, Brasil E-mail: nilton.marengoni@unioeste.br 


\author{
Elenice Souza dos Reis Goes \\ ORCID: https://orcid.org/0000-0003-2437-4800 \\ Universidade Federal da Grande Dourados, Brasil \\ E-mail: elenicegoes@ufgd.edu.br \\ Maria Luiza Rodrigues de Souza \\ ORCID: https://orcid.org/0000-0001-5643-0841 \\ Universidade Estadual de Maringá, Brasil \\ E-mail:mlrsouza@uem.br
}

\begin{abstract}
Resumo
O objetivo deste trabalho foi avaliar o desempenho produtivo e parâmetros físico-mecânicos do couro de tilápias do Nilo, influenciados pela inclusão de SL491* (à base de própolis) nas rações. Conduziu-se um experimento contendo seis tratamentos $(0,50,100,150,200$ e $250 \mathrm{~g}$ de SL491* / $100 \mathrm{~kg}$ de ração) e quatro repetições, sendo a unidade experimental composta por uma caixa de $500 \mathrm{~L}$ contendo quatro peixes (peso inicial $13 \mathrm{~g}$ ). Após 160 dias, os peixes foram pesados e medidos para análises do desempenho produtivo, e processados até a retirada das peles, que foram submetidas ao curtimento. Os parâmetros físico-químicos da água não diferiram entre os tratamentos, já em relação ao desempenho produtivo, a adição de SL491* promoveu um efeito positivo no peso dos peixes, no ganho de peso médio, no entanto não interferiu na conversão alimentar. O rendimento de filé, pele bruta e pele limpa sem escamas, não foram influenciados pela adição de SL491*. Quando avaliado os parâmetros da qualidade dos couros, a espessura, a força máxima aplicada no teste e o rasgamento progressivo aumentaram com o acréscimo do produto SL491* à base de própolis na ração. Não houve influência da adição de SL491* na ração quanto aos parâmetros de força máxima aplicada na determinação da tração e alongamento, para a elasticidade (alongamento), para a resistência a tração e a deformação específica até a ruptura do couro. Conclui-se que a inclusão de até $200 \mathrm{~g}$ de SL491*/100kg de ração promove efeito positivo no desempenho de tilápias e na qualidade final dos couros.
\end{abstract}

Palavras-chave: Alongamento; Oreochromis niloticus; Tração.

\begin{abstract}
The objective of this work was to evaluate the productive performance and physical-mechanical parameters of Nile tilapia leather, influenced by the inclusion of SL491* (based on propolis) in the rations. An experiment was conducted with six treatments $(0,50,100,150,200$ and $250 \mathrm{~g}$ of SL491*/100 kg of feed) and four replications, the experimental unit being composed of a $500 \mathrm{~L}$ box containing four fish (weight initial $13 \mathrm{~g}$ ). After 160 days, the fish were weighed and measured to analyze their productive performance, and processed until the skins were removed, which were subjected to tanning. The physical-chemical parameters of the water did not differ between treatments, in relation to productive performance, the addition of SL491* promoted a positive effect on fish weight, on average weight gain, however it did not interfere with feed conversion. The fillet yield, raw skin and clean skin without scales were not influenced by the addition of SL491*. When the parameters of the quality of the hides were evaluated, the thickness, the maximum force applied in the test and the progressive tearing increased with the addition of the SL491* product based on propolis in the ration. There was no influence of the addition of SL491* in the ration regarding the parameters of maximum applied force in determining traction and elongation, for elasticity (elongation), for tensile strength and specific deformation until leather rupture. It is concluded that the inclusion of up to $200 \mathrm{~g}$ of SL491*/100kg of feed promotes a positive effect on the performance of tilapia and on the final quality of the hides.
\end{abstract}

Keywords: Oreochromis niloticus; Stretching; Traction.

\title{
Resumen
}

El objetivo de este trabajo fue evaluar el comportamiento productivo y parámetros físico-mecánicos del cuero de tilapia del Nilo, influenciado por la inclusión de SL491* (a base de propóleo) en las raciones. Se realizó un experimento con seis tratamientos $(0,50,100,150,200$ y $250 \mathrm{~g}$ de SL491*/ $100 \mathrm{~kg}$ de pienso) y cuatro repeticiones, estando la unidad experimental compuesta por una caja de $500 \mathrm{~L}$ conteniendo cuatro peces (peso inicial 13 gramo). Luego de 160 días, los peces fueron pesados y medidos para analizar su desempeño productivo, y procesados hasta que se retiraron los hollejos, los cuales fueron sometidos a curtido. Los parámetros físico-químicos del agua no difirieron entre tratamientos, en relación al desempeño productivo, la adición de SL491* promovió un efecto positivo en el peso de los peces, en la ganancia de peso promedio, sin embargo no interfirió con la conversión alimenticia. El rendimiento de filete, la piel en bruto y la piel limpia sin escamas no se vieron afectados por la adición de SL491*. Cuando se evaluaron los parámetros de la calidad de los cueros, el espesor, la fuerza máxima aplicada en la prueba y el desgarro progresivo aumentaron con la adición del producto SL491 * a base de propóleo en la ración. No hubo influencia de la adición de SL491* en la ración con respecto a los parámetros de fuerza máxima aplicada para determinar la tracción y elongación, para la elasticidad (elongación), para la resistencia a la tracción y la deformación específica hasta la rotura del cuero. Se concluye que la inclusión de hasta $200 \mathrm{~g}$ de SL491 * / 100kg de pienso promueve un efecto positivo en el comportamiento de la tilapia y en la calidad final de las pieles.

Palabras clave: Estiramiento; Oreochromis niloticus; Tracción. 


\section{Introdução}

Nos últimos anos a piscicultura no Brasil vem crescendo de maneira vigorosa nos setores da produção e profissionalização, e em 2020, a produção de peixes cultivados no Brasil alcançou a marca de 802.930 toneladas, gerando cerca de 8 bilhões de reais e cerca de 1 milhão de empregos diretos e indiretos (Peixe-Br, 2021). A tilápia do Nilo (Oreochromis niloticus) é destaque na piscicultura por possuir carne de alta aceitabilidade e fácil potencial de cultivo, apresentando se como o quarto maior produtor do Brasil, correspondendo a 60,6\% da produção do país (Peixe-Br, 2021).

Segundo Silva et al. (2009), a tilápia do Nilo de 250 a $600 \mathrm{~g}$ de peso corporal, representa um rendimento de carcaça de 59,39\%, tendo um peso médio de filé de 269,36 gramas, correspondendo a um rendimento de filé de 34,18\%. Para os resíduos de filetagem a cabeça representa $21 \%$, nadadeiras $3,9 \%$, pele $5,9 \%$, vísceras $12,4 \%$ e outros resíduos $10 \%$, sendo todos esses resíduos descartados de forma irregular, consequentemente gerando problemas sanitários e ambientais para indústrias e produtores (Matiucci et al., 2020). Embora, sendo uma espécie introduzida no Brasil, a tilápia do Nilo é sem dúvida uma espécie com potencial na piscicultura industrial. A tilápia é considerada uma das espécies mais promissoras para a piscicultura, pelo rápido crescimento, por possuir carne de alta aceitabilidade pelo consumidor e tolerância a diversas condições de criação (Barroso et al., 2017).

Os problemas sanitários são muito frequentes em cultivos intensivos, devido às altas densidades, elevado arraçoamento, proporcionando maior quantidade de matéria orgânica, consequentemente amônia, nitrito entre outros. Portanto, se faz necessário mais estudos que visem minimizar os impactos sofridos nesses sistemas, tendo em vista que a piscicultura corresponde atualmente ao setor de produção de alimentos que mais cresce no mundo (Silva, 2016).

Devido às condições de criação em sistemas intensivos promoverem situações que interferem negativamente no desempenho animal, tem-se aumentado a preocupação com as condições sob as quais os peixes são criados e as implicações que isso pode acarretar na qualidade do produto final (Carvalho et al.,2006; Rijkers et al., 1981). O uso de aditivos nas rações pode promover um maior crescimento, melhorar o estado sanitário e fisiológico dos peixes, minimizando dessa forma as mortalidades e o desenvolvimento insatisfatório, e melhorando assim a eficiência alimentar. Os antibióticos representam um grupo de compostos de estrutura química heterogenia, propriedade físico-química e aspectos diferentes, tendo como único ponto comum, a capacidade antibacteriana (Andriguetto et al., 1989; Grassi, 2014). Já a própolis é um produto constituído por uma mistura de diversas resinas vegetais, as quais são coletadas pelas abelhas em plantas comumente visitadas por insetos (Bianchini et al., 1998) e a própolis tem inúmeras ações destacando-se as: antimicrobiana (em especial bactérias Gram positivas), anti-HIV, antiviral, antifúngica, antiparasitária e antiinflamatória. Possui ação antisséptica, bacteriostática e adstringente (Bankova et al., 1989; Moreno et al., 1999; Castaldo \& Capasso, 2002).

A palavra própolis significa "em defesa da cidade" e constitui-se uma resina balsâmica produzida pelas abelhas com o intuito de proteger a colmeia. Os constituintes solúveis da própolis, obtidos utilizando-se solventes orgânicos, constituem-se em 50 a $80 \%$ de resinas e bálsamos aromáticos, 4,5 a $15 \%$ de óleos voláteis e outras substâncias voláteis, 12 a $50 \%$ de cera, 4 a 10,5\% de substâncias tônicas, níveis inferiores a 15\% de impurezas mecânicas (lascas de madeiras, tinta, pedaços de insetos, folhas e terra), e 5 a $11 \%$ de pólen viabilizando a produção de formas de aplicação da própolis como alternativa de aditivos para rações de peixe em crescimento (Vanhaelen et al., 2007).

A composição da própolis varia de acordo com zona geográfica e a flora existente ao redor do apiário (Markham et al., 1996), sendo necessário uma eficiente caracterização dos seus compostos visando à padronização deste elemento, sendo necessários estudos com relação à caracterização, extração, concentração e reprodutibilidade do extrato de própolis a ser utilizado (Tiveron, 2015).

A variação na composição da própolis é relatada na presença de compostos aromáticos, derivados do ácido benzoico, derivados do ácido e do álcool cinâmico (Greenaway et al., 1987; Garcia-Viguera et al., 1992), derivados do benzaldeído 
(Bankova et al., 1992), compostos terpênicos (Vanhaelen \& Vanhaelen-Fastri 1979a), compostos agliconas, derivados de flavonóis e flavonas (Vanhaelen \& Vanhaelen-Fastri, 1979a; Bankova et al., 1983), flavononas (Greenaway et al., 1991; Marcucci, 1995), dihidroflavonois (Vanhaelen \& Vanhaelen-Fastri, 1979b). Considerando a composição de substâncias químicas com propriedades farmacêuticas, apesar de serem encontrados mais de 25 flavonóides agliconas (flavonas, flavonóis, flavononas e dihidroflavonois), em amostras de própolis de diferentes origens, não foram encontrados mais que $14 \mathrm{em}$ amostras individuais.

Entre os compostos químicos presentes na própolis se destacam os flavonóides (Castaldo \& Capasso, 2002), que segundo Grange e Davey (1990) estão relacionados com a atividade antibacteriana da própolis. A composição das própolis é avaliada pelo grupo dos flavonóides que é considerado o grupo químico majoritário da própolis (flavonas, flavonóis, flavanonas e dihidroflavonois) e é descrito como tendo atividade antibacteriana e antiprotozoária (Cabral et al., 2009).

A própolis também atua na forma de tratamento de grande importância por suas propriedades farmacêuticas como antioxidante (Koltuksuz, 1999; Orhan et al., 1999), cicatrizante (Magro Filho \& Carvalho, 1990), antiinflamatória (Burdock, 1998) e antimicrobiana (Koo, 2000). No âmbito dos estudos zootécnicos, tem se observado bons resultados com relação à própolis no controle de Eimeria em coelhos (Moura et al., 1998) e Salmonela em frangos de corte, (Mazzuco et al., 1996). Contudo, os estudos existentes ainda são poucos, devendo essa substância ser melhor estudada para se ter adequado respaldo científico.

Considerando, as tendências da busca de alternativas e visando um maior desempenho dos peixes, a utilização do produto SL491* adicionado nas rações surge com grande potencial e segundo Pereira et al. (2002) ressaltam a preocupação do interesse global, nas pesquisas referente à esse produto, pela justificativa da característica de panaceia e também do altíssimo valor agregado proferido. A pele é composta por fibras colágenas e a própolis parece ativar os fibroblastos, estimulando o desenvolvimento das fibras colágenas. De acordo com Paixão et al. (2014) existem evidências do efeito da própolis na aceleração do processo de reparo tecidual, mas não só devido à ação antiinflamatória, como mostram vários estudos, mas também por sua ação diretamente na proliferação de fibroblastos, dessa forma proporciona o aceleramento da reversão de fibrócito em fibroblasto, favorecendo a síntese e deposição de fibras colágenas, consequentemente melhorando o reparo tecidual e reduzindo o tempo de cicatrização. Dessa forma, a pele já apresenta como característica peculiar a sua resistência, principalmente por ser o maior órgão, responsável pelo revestimento superficial do corpo servindo como uma barreira que impede a entrada de substâncias perigosas no corpo e exerce muitas funções importantes, tais como protegendo contra as agressões externas, manutenção do equilíbrio hídrico e eletrolítico, percepção de estímulos, entre outros.

A pele de peixe pode ser curtida para aumentar a sua resistência (Larezzi, 1988), e quando comparada em uma mesma espessura com o couro bovino, apresenta maior resistência devido à forma de entrelaçamento e disposição das fibras colágenas (Adeodato, 1995).

Além dessa característica, após sofrer o processo de curtimento, as lamélulas de proteção onde se inserem as escamas presentes nesse tipo de pele, faz com que o couro de peixe curtido apresente um aspecto típico (Jacinto \& Ferrari, 1992), e difícil de ser imitado, garantindo um padrão exclusivo para o produto após seu processamento (Adeodato, 1995).

Devido ao grande potencial e crescimento da aquicultura brasileira, experimentos que visem à melhoria no desempenho das espécies e utilização de subprodutos se fazem necessários, uma vez que podem promover uma melhoria na qualidade e no aproveitamento dos produtos e subprodutos dessa cultura (Silva \& Galício, 2012).

Tendo em vista que a produção brasileira de própolis é a terceira do mundo perdendo apenas para a Rússia e a China. E analisando as propriedades farmacológicas, características organolépticas positivas, menores teores de metais pesados e outros poluentes ambientais, além da busca por produtos naturais que possam agir da mesma maneira que os produtos sintéticos em geral, porém que não causem problemas para os peixes e para as pessoas que vão consumir seus produtos. A própolis aparece como uma alternativa de produto orgânico a ser avaliado em pesquisas para o uso na produção animal (Pereira et al., 2002). 
Ciente desta necessidade a presente pesquisa justificou-se pela necessidade da busca de produtos alternativos para o desenvolvimento e aumento da produtividade do setor de piscicultura buscando à adequação com produtos considerados orgânicos, uma vez que alimentos desprovidos de produtos químicos é uma tendência mundial, buscando uma melhor qualidade de vida aos seres humanos e peixes.

O objetivo desta pesquisa foi avaliar o desempenho dos peixes e as características físico-mecânicas dos couros da tilápia do Nilo (Oreochromis niloticus) alimentadas com rações com diferentes níveis de inclusão de própolis em pó (produto SL491*).

\section{Metodologia}

\section{Coleta e preparo da própolis}

As própolis que foram utilizadas neste experimento foram coletadas na região do Distrito de Iguatemi (Paraná - Brasil) e do município de Mandaguaçu (Paraná - Brasil), no apiário da Fazenda Experimental de Iguatemi, da Universidade Estadual de Maringá, e selecionadas no Laboratório do Setor de Apicultura.

As amostras de própolis foram coletadas através de uma suave raspagem sobre as diversas partes das caixas com formão de aço inox, homogeneizadas, trituradas e acondicionadas em sacos plásticos e armazenadas à $-18^{\circ} \mathrm{C}$, em freezer.

O produto SL491* foi realizado no Laboratório de Farmacotécnica da UEM, de acordo com metodologia desenvolvida por Franco e Bueno (1999), cujo pedido de patente é RPI - 1851/PI - 05063930.

\section{Período e execução do experimento}

O experimento foi conduzido na Estação de Piscicultura da UEM/CODAPAR situada no Distrito de Floriano (Paraná Brasil), e o processamento das peles e os testes físico-mecânicos do couro foram executados no Laboratório de Processamento de Peles situado na Fazenda Experimental de Iguatemi da Universidade Estadual de Maringá. O período experimental foi de aproximadamente 160 dias, utilizando-se de 96 exemplares de tilápia do Nilo revertidas sexualmente, com peso médio inicial de 13g. Os peixes foram distribuídos aleatoriamente em 24 caixas de cimento amianto com capacidade de $500 \mathrm{~L}$. Em um delineamento inteiramente casualizado composto por seis tratamentos e quatro repetições. Cada caixa de amianto com quatro peixes foi considerada uma unidade experimental. As caixas possuíam sistema de circulação de água por gotejamento. Os peixes foram alimentados com seis rações diferentes, sendo cada um referente à um tratamento. Portanto, seis tratamentos $($ Trat $1=0 \mathrm{~g}$, Trat2 $=50 \mathrm{~g}$, Trat $3=100 \mathrm{~g}$, Trat $4=150 \mathrm{~g}$, Trat $5=200 \mathrm{~g}$ e Trat $6=250 \mathrm{~g}$ de produto $\mathrm{SL} 491^{*}$, à base de própolis). As rações foram formuladas de acordo com as exigências nutricionais para a tilápia do Nilo (Oreochromis niloticus) e na Tabela 1 encontra-se a sua composição. 
Tabela 1 - Composição percentual da ração referência.

\begin{tabular}{|c|c|}
\hline Ingredientes & $(\%)$ \\
\hline Milho & 43,50 \\
\hline Farelo de Soja & 40,00 \\
\hline Farinha de peixe & 2,23 \\
\hline Fosfato bicálcico & 3,00 \\
\hline L-lisina HCL & 0,30 \\
\hline DL- metionina & 0,10 \\
\hline Suplemento mineral e vitamínico ${ }^{1}$ & 0,50 \\
\hline Vitamina $\mathrm{C}^{2}$ & 0,05 \\
\hline Sal comum & 0,50 \\
\hline $\mathrm{BHT}^{3}$ & 0,02 \\
\hline Alginato $^{4}$ & 0,10 \\
\hline Total & 100,00 \\
\hline \multicolumn{2}{|c|}{ 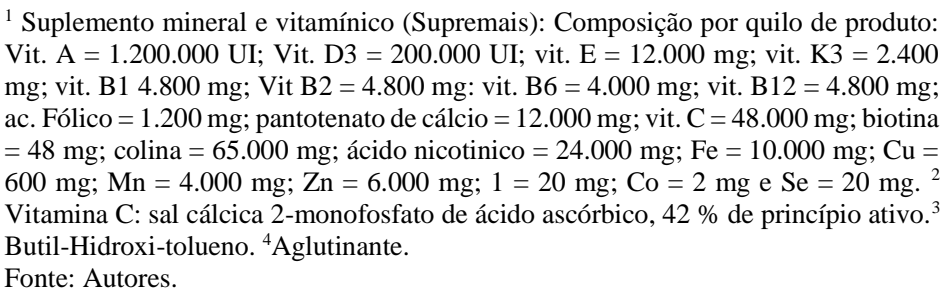 } \\
\hline
\end{tabular}

O produto SL491* foi preparado na base de 30\% para os seis níveis de inclusão das rações (Trat1=0g; Trat2=50g; Trat3=100g; Trat4=150g; Trat5=200g; Trat6=250g/100kg de ração).

Para efeito de duplo-cego às amostras da SL491* foram entregues aleatoriamente e distribuídas nas rações sendo denominadas por A, B, C, D, E e F (cinco níveis e uma testemunha). Os demais ingredientes utilizados na formulação da ração foram moídos individualmente em moinho tipo faca, com peneira de 0,5 mm (Hayashi et al., 1999). Todos os ingredientes foram homogeneizados, umedecidos, peletizados e secos em estufa de ventilação forçada.

$\mathrm{O}$ arraçoamento foi controlado na porcentagem de $5 \%$ da biomassa, realizado duas vezes ao dia $(2,5 \%$ pela manhã e 2,5 à tarde) e periodicamente foram realizadas pesagens aleatórias dos lotes para correção da quantidade de ração a ser fornecida. Diariamente foram tomados os parâmetros de temperatura (manhã e tarde) e mensalmente foram mensurados os parâmetros físico-químicos de pH, oxigênio dissolvido, amônia, saturação de bases, alcalinidade, dureza e gás carbônico. A sifonagem das caixas foi realizada periodicamente para retirada das excretas e sobras de ração.

\section{Parâmetros avaliados}

Ao final do período experimental, para os abates, todos os indivíduos foram insensibilizados com choque térmico, em caixas isotérmicas com gelo moído e água, (1:1); pesados e medidos para as mensurações do peso final médio, peso do filé, peso da pele, peso da pele limpa sem escamas. Aprovado pelo comitê de ética animal protocolado sob o CEUA nº 9818130619 (ID 002268).

Após essas mensurações foram calculados o ganho de peso médio, a conversão alimentar, os rendimentos de filé, as porcentagens de pele bruta e pele limpa sem escamas.

Após as mensurações de desempenho foram retiradas as peles dos peixes e colocadas individualmente em saco plástico, identificadas e congeladas até o momento da realização do processo de curtimento.

No momento de iniciar o curtimento, as peles foram identificadas com auxílio de miçangas, fixadas à pele, por meio de uma linha mercê no 60 . 


\section{Processo de curtimento das peles}

A partir do peso das peles, foram calculadas as quantidades de água e de produtos químicos que foram adicionados nas etapas do processo de curtimento. O processo que foi aplicado às peles constou das seguintes etapas: remolho, caleiro, desencalagem, purga, piquel, curtimento, neutralização, recurtimento, tingimento, engraxe, secagem e acabamento. As etapas do processo de curtimento com suas finalidades estão listadas abaixo de acordo com Hoinacki et al. (1994) e Souza (2004).

O remolho é o processo de hidratação e lavagem das peles. Nesse processo as peles foram submetidas ao tratamento com solução composta de $200 \%$ de água e 0,5\% de tensoativo, por 30 minutos. Em seguida foi esgotado o fulão (equipamento em forma de tambor utilizado para o curtimento) e lavadas as peles.

O caleiro é o processo onde ocorre o intumescimento das peles, proporcionando à abertura das fibras colágenas e a liberação das escamas. Nesse processo as peles foram submetidas ao tratamento com solução composta de 200\% de água, $3 \%$ de sulfeto de sódio, 3\% de cal hidratada e 0,5\% de tensoativo, por 12 horas. Depois foi esgotado o banho do fulão e as peles submetidas a lavagens sucessivas para redução do teor de cal adicionada na etapa de caleiro.

A desencalagem é o processo onde ocorre a eliminação das substâncias alcalinas e proporciona o afrouxamento da estrutura fibrilar. Nesse processo as peles foram submetidas ao tratamento com solução composta de $100 \%$ de água, $2 \%$ de Bascal ${ }^{\circledR}$, por 20 minutos. A cada 20 minutos foi adicionado $2 \%$ de Bascal ${ }^{\circledR}$ até atingir o pH em torno de 8,0 a 8,5.

A purga é o processo de limpeza da estrutura fibrosa através de substâncias proteolíticas, nesse processo as peles foram submetidas ao tratamento com solução composta de $100 \%$ de água a $32{ }^{\circ} \mathrm{C}$ e $1 \%$ de Koropon MK® por 40 minutos, depois deste período foi adicionado $1 \%$ de Bascal ${ }^{\circledR}$ para atingir o pH em torno de 6,8. Após atingir o pH esperado, foi esgotado o fulão e lavadas as peles.

O desengraxe é o processo que remove o excesso de gordura ainda presente na estrutura dérmica. Nesse processo as peles foram submetidas ao tratamento com solução composta de $100 \%$ de água e $0,5 \%$ de tensoativo, por 30 minutos. O processo foi repetido por mais duas vezes de 30 minutos cada.

O píquel é o processo que acidifica as fibras colágenas para reagirem com o agente curtente. Nesta etapa as peles foram submetidas a solução composta de $100 \%$ de água, $20 \%$ de cloreto de sódio $\left(7,0^{\circ}\right.$ Bé), por 10 minutos, depois foi adicionado $2,25 \%$ de ácido fórmico diluído em água (1:10), parceladamente em três vezes. O período dessa etapa durou 60 minutos, cujo pH ficou em 3,0 .

O curtimento é o processo que proporciona à estabilidade de todo o sistema colágeno, aumentando a temperatura de retração, diminuindo a capacidade de intumescimento do colágeno e estabilização face às enzimas. Nesta etapa as peles foram submetidas a solução composta de $6 \%$ de chromossal $\mathrm{B} \circledast$, por duas horas em fulão com rotação, após este período as peles pernoitaram em banho estático dentro do fulão. A basificação é realizada para fixar o curtente nas fibras colágenas. Para a basificação foi adicionado 1,0\% de bicarbonato de sódio, diluido em água (1:10) e adicionado em três vezes, até atingir pH = 3,9-4,0, com rotação do filão por 60minutos, após atingir esse $\mathrm{pH}$ desejado. Depois os couros foram deixados de repouso no banho por cinco horas e mais 12 horas fora do banho, para complementação do processo de reticulação do cromo com as fibras colágenas (Hoinacki, 1989).

A neutralização ou desacidificação é o processo que elimina o excesso de acidez do couro. Nesse processo os couros foram submetidos à solução composta de $100 \%$ de água e $1 \%$ de bicarbonato de sódio, por 60 minutos. Após esse período foi esgotado o fulão e lavado os couros.

O recurtimento e tingimento são os processos que proporcionam maior maciez ao couro e determinam a cor final de couro. Nestas etapas os couros foram submetidos ao banho composto de $150 \%$ de água e $4 \%$ Weibull@ por 40 minutos.

Passado esse período adicionou-se 3\% de corante e esperou-se mais 30 minutos, para melhor penetração do corante. Após esse período esgotou-se a solução do fulão. 
O engraxe é o processo que proporciona a maciez e elasticidade ao couro pela ação dos óleos envolvendo as fibras colágenas, evitando a aglutinação das mesmas. Nesse processo os couros foram submetidos ao tratamento com solução composta de $150 \%$ de água a $60{ }^{\circ} \mathrm{C}, 4 \%$ de Lipodermilicker LA NAE $®$ e $4 \%$ de Lipodermilicker LA - 2®, por 60 minutos. Após esse período, adicionou-se 1,0\% de ácido fórmico, diluído na proporção 1:10 e parcelado em três vezes a cada dez minutos. Após a fixação do engraxe e do corante com adição dos ácidos, esgotou-se a solução do fulão e os couros prontos foram lavados.

Terminado o processo de curtimento, os couros foram submetidos a secagem, realizada à temperatura ambiente para reduzir o teor de água.

\section{Análises físico-mecânico dos couros}

Para as avaliações da resistência dos couros de tilápia, foram retirados corpos de prova para a realização dos testes de determinação de tração e alongamento (ABNT-NBR ISSO 3376, 2014) e rasgamento progressivo (ABNT-NBR 3377-2, 2014).

Os corpos de provas foram retirados dos couros no sentido longitudinal ao comprimento, com uso de um balancim. Em seguida, foram levados para o laboratório com ambiente climatizado em torno de $23^{\circ} \mathrm{C}$ e umidade relativa do ar de $50 \%$, por 24 horas (ABNT-NBR 10455, 2021). Após este período, foram determinadas as medidas de espessura de cada amostra (ABNTNBR 11114, 2020) para os cálculos de resistência à tração, alongamento e rasgamento progressivo.

Para a realização destes testes de resistência, foi utilizado o dinamômetro da marca EMIC, com velocidade de afastamento entre as cargas de $100 \square 20 \mathrm{~mm} / \mathrm{min}$. A célula de carga usada no dinamômetro foi $200 \mathrm{Kgf}$. O equipamento foi submetido à calibração pela EmicDcame, laboratório de calibração credenciado pela CGCRE/inmetro sob nº 197.

\section{Análise estatística}

Os dados obtidos foram submetidos à análise de variância ao nível de 5\% de probabilidade e os níveis de inclusão foram avaliados por meio de análise de regressão utilizando o auxílio do programa estatístico Statistical Analysis System (SAS Inst. Inc., Cary, NC, USA, 2010)

\section{Resultados e Discussão}

\section{Qualidade da água}

A temperatura média da água no período experimental foi de 19,$8 ; 15,8 ; 19,1$ e $19,2^{\circ} \mathrm{C}$ nos quatro meses analisados, sendo considerada baixas as temperaturas para um bom desenvolvimento da espécie estudada. Isto ocorreu em função do período que o experimento foi realizado, de maio a agosto. A temperatura entre 26 a $28^{\circ} \mathrm{C}$ é considerada mais favorável para o desenvolvimento de tilápia (Kubitza, 2000). Os parâmetros físico-químicos da água não diferiram significativamente entre os tratamentos, podendo ser verificado na Tabela 2. 
Tabela 2 - Medidas dos parâmetros da qualidade da água durante o período experimental.

\begin{tabular}{lllllll}
\hline & \multicolumn{7}{c}{ Variáveis } \\
\cline { 2 - 7 } Tratamentos & $\begin{array}{l}\text { Oxigênio } \\
\text { Dissolvido } \\
\text { inicial/final }^{1} \\
(\mathrm{mg} / \mathrm{L})\end{array}$ & $\begin{array}{l}\text { Alcalinidade } \\
\text { Total } \\
\text { inicial/final } \\
(\mathrm{mg} / \mathrm{L})\end{array}$ & $\begin{array}{l}\text { Dureza } \\
\text { inicial/final } \\
(\mathrm{mg} / \mathrm{L})\end{array}$ & $\begin{array}{l}\mathrm{CO}_{2} \\
\text { inicial/final } \\
(\mathrm{mg} / \mathrm{L})\end{array}$ & $\begin{array}{l}\text { Amônia } \\
\text { inicial/final } \\
(\mathrm{mg} / \mathrm{L})\end{array}$ & $\begin{array}{l}\mathrm{pH} \\
\text { final }\end{array}$ \\
\hline Trat1=0g & $6,30-9,65$ & $66-114$ & $81-70,5$ & $8-4$ & $0,25-0,00$ & $7,2-7,2$ \\
Trat2=50g & $7,23-10,78$ & $57-109$ & $72-73,5$ & $8-4$ & $0,20-0,00$ & $7,2-7,5$ \\
Trat3=100g & $6,27-9,61$ & $57-117$ & $78-75$ & $8-4$ & $0,00-0,00$ & $7,2-7,2$ \\
Trat4=150g & $7,01-9,89$ & $57-121,5$ & $54-69$ & $8-5$ & $0,00-0,00$ & $7,0-7,2$ \\
Trat5=200g & $6,36-8,79$ & $104-117$ & $81-78$ & $8-4$ & $0,20-0,00$ & $7,2-7,2$ \\
Trat6=250g & $6,51-9,02$ & $57-112,5$ & $66-78$ & $8-5$ & $0,00-0,00$ & $7,2-7,5$ \\
\hline Teste F & $\mathrm{ns}$ & $\mathrm{ns}$ & $\mathrm{ns}$ & $\mathrm{ns}$ & $\mathrm{ns}$ & $\mathrm{ns}$ \\
\hline
\end{tabular}

${ }^{1}$ Médias obtidas na fase inicial e final para cada parâmetro da água avaliado. ns - Não significativo a 5\% de probabilidade. Fonte: Autores.

As concentrações de oxigênio dissolvido (OD) variaram de 4,40 a 10,78 mg/L, estes valores são considerados superiores a concentração mínima de OD necessárias para manter o crescimento ótimo da tilápia. De acordo com Pereira e Silva (2012) o nível preconizado de oxigênio dissolvido na produção de tilápias deve ser acima de $4 \mathrm{mg} / \mathrm{L}$. Portanto, os níveis observados durante o período experimental foram condizentes com o recomendado para a criação de tilápia.

Santos et al. (2013) também realizaram avaliação de extrato de própolis na ração para alevinos de tilápia do Nilo para avaliação do desempenho. Os autores mencionaram que os valores médios de temperatura, oxigênio dissolvido, pH, nitrito e amônia foram de $27,3 \pm 1,1^{\circ} \mathrm{C} ; 5,8 \pm 2,0 \mathrm{mg} / \mathrm{L} ; 7,1 \pm 0,3 ; 0,25 \pm 0,10 \mathrm{mg} / \mathrm{L} ; 0,003 \pm 0,003 \mathrm{mg} / \mathrm{L}$, respectivamente, sendo que no período experimental, esses parâmetros de qualidade de água do sistema mantiveram-se dentro da faixa de conforto para a tilápia do Nilo, de acordo com o preconizado por Kubitza (2000). Ficando apenas a temperatura da água abaixo do recomendado neste experimento, em função do período que foi realizado o experimento (Tabela 2).

$\mathrm{O}$ pH da água variou de 7,0 a 7,5, a alcalinidade total de 57 a 121,5 mg/l, a dureza total de 54 a $81 \mathrm{mg} / \mathrm{L} \mathrm{e} \mathrm{o} \mathrm{CO2} \mathrm{de} 4$ a $8 \mathrm{mg} / \mathrm{L}$ (Tabela 2), sendo estes valores próximos aos recomendados para a criação de tilápias (Popma \& Green, 1994). Os parâmetros permaneceram dentro da faixa recomendada por Popma e Green (1994) para máximo desempenho das tilápias, exceto a temperatura que foi inferior ao recomendado nos quatro meses do período experimental.

\section{Desempenho dos peixes}

$\mathrm{Na}$ Tabela 3 constam os valores referentes ao peso médio dos peixes nos quatro períodos analisados, sendo que nos três primeiros meses não houve efeito da adição de SL491*. Já o quarto período houve diferença significativa para o peso médio dos peixes analisados (Tabela 3).

Tabela 3 - Valores médios dos pesos dos peixes alimentados com rações com diferentes níveis de adição da SL491* à base de própolis.

\begin{tabular}{lllllllll}
\hline Períodos & \multicolumn{9}{c}{ Peso $(\mathrm{g})$} \\
\cline { 2 - 9 } & Trat1 & Trat2 & Trat3 & Trat4 & Trat5 & Trat6 & $\begin{array}{l}\text { Valor } \\
\text { de P }\end{array}$ & CV (\%) \\
\hline P1* & 35,33 & 34,52 & 35,54 & 35,36 & 33,93 & 35,97 & 0,2735 & 11,17 \\
P2 & 38,08 & 37,37 & 39,27 & 39,50 & 37,17 & 39,39 & 0,5872 & 13,32 \\
P3 & 66,53 & 65,74 & 67,06 & 66,40 & 65,23 & 62,54 & 0,9734 & 16,78 \\
P4 & 130,10 & 134,26 & 143,37 & 145,85 & 160,44 & 149,84 & 0,0005 & 14,98 \\
\hline
\end{tabular}

*P - mês de experimento ( $1=$ maio; $2=$ junho; $3=$ julho e $4=$ agosto). Fonte: Autores. 
Há indícios de que adição da SL491* pode ser adicionada até o nível Trat5, pois se notou um aumento de peso dos peixes na mesma ordem crescente de adição da SL491*, tendo um decréscimo $(149,84 \mathrm{~g})$ no tratamento Trat6, que possuía o maior nível de inclusão da SL491*, indicando um possível efeito inibitório do composto neste nível com 250g/100kg de ração.

Embora sejam necessários mais estudos sobre as propriedades farmacológicas da própolis em peixes, os resultados desta pesquisa concordam com Biavatti et al. (2003). De acordo estes autores a própolis foram eficazes em frangos, apresentando melhores desempenhos a partir de 14 a 21 dias de idade. Afirmam que os resultados desse estudo sugerem que o extrato de própolis pode ser usado como agente antimicrobiano, uma vez que eles melhoraram o desempenho das aves. Mas, acima de tudo estes autores recomendam a necessidade de mais estudos para encontrar uma adequada concentração a ser adicionada na dieta. Santos et al. (2003) também avaliaram a própolis em frangos de corte. Os autores relataram que o uso do resíduo de própolis até 2,86\% na ração, proporcionou um aumento no ganho de peso das aves, na fase de 1 a 21 dias, enquanto que utilizando de 1 a 42 dias, com o aumento do resíduo de própolis na dieta, houve uma redução no ganho de peso e piorou a conversão alimentar dos frangos de corte. Isso ocorreu provavelmente devido ao teor de fibra presente no resíduo (14,41\%) e ceras $(26,76 \%)$.

Pode-se observar que a própolis está sendo utilizada frequentemente na área da medicina humana e animal, com obtenção de bons resultados (Matucci et al., 2021; Rivero et al., 2019; Morreira et al.,2018), mas, para qualquer que seja o objetivo do uso da própolis, deve-se investigar os melhores níveis de utilização.

Com relação ao ganho de peso médio dos peixes nos três intervalos analisados (Tabela 4), foi observada apenas a diferença significativa entre os ganhos de peso médios dos peixes, no $3^{\circ}$ intervalo (P3-P4), sendo que os tratamentos Trat1 $(69,72 \mathrm{~g})$, Trat2 (71,75g), Trat3 (76,31g) e Trat4 $(77,10 \mathrm{~g})$ apresentaram médias inferiores em relação ao tratamento Trat5 (99,34g). mostrando que houve um efeito positivo até à adição de 200,0g de própolis na ração. Por este parâmetro também é possível visualizar indícios de que adição da SL491* pode ser adicionada até o nível utilizado no Trat5 (200g/100kg de ração), pois se nota que o nível mais alto, Trat6, não diferenciou significativamente dos tratamentos Trat1, Trat2, Trat3 e Trat4.

Tabela 4 - Valores médio de ganho de peso dos peixes nos intervalos alimentados com diferentes níveis de inclusão da SL491* a base de própolis.

\begin{tabular}{lllllllll}
\hline Intervalo & \multicolumn{8}{c}{ Ganho de peso (g) } \\
\cline { 2 - 10 } & Trat1 & Trat2 & Trat3 & Trat4 & Trat5 & Trat6 & $\begin{array}{l}\text { Valor } \\
\text { de P }\end{array}$ & CV (\%) \\
\hline P1-P2* & 2,74 & 2,85 & 3,73 & 4,13 & 3,24 & 3,42 & 0,459 & 21,44 \\
P2-P3 & 28,45 & 28,38 & 27,80 & 26,90 & 28,06 & 27,00 & 0,964 & 12,13 \\
P3-P4 & 69,72 & 71,75 & 76,31 & 77,10 & 99,34 & 87,33 & 0,005 & 15,78 \\
\hline
\end{tabular}

*P1-P2 - período de maio a junho; P2-P3- período de junho a julho e P3-P4- período de julho a agosto. Fonte: Autores.

Não foram observados efeitos significativos $(\mathrm{P}>0,05)$ da utilização de rações com diferentes níveis de inclusão da SL491* sobre a conversão alimentar, cujos valores variam de 1,10 a 1,88 entre os diferentes tratamentos.

Os resultados encontrados neste trabalho podem ter relação com a composição química da própolis que é muito variada e complexa, estando relacionada com o período de coleta de resina para o preparo do produto, assim como a forma de preparo e mesmo a dosagem utilizada.

Não houve influência do nível de própolis utilizada na ração em relação ao rendimento de filé, de pele bruta e pele limpa (sem as escamas), (Tabela 5). Os valores médios do rendimento de filé (29,90\%) estão dentro dos resultados obtidos Souza (2002), cujo rendimento variou de 33,66 \% a 34,94 \% em função do método de filetagem utilizado. Já, Ribeiro et al. (1998) relataram como rendimento mínimo de $26,32 \%$ e o máximo de $37,08 \%$, para tilápia vermelha (Oreochromis niloticus). O rendimento médio da pele $(8,65 \%)$ e pele limpa sem escamas $(3,42 \%)$ diferiram dos encontrados por Souza (2002), que foram $7,67 \%$ e $4,14 \%$, respectivamente. 
Tabela 5 - Valores médios do rendimento de carcaça dos peixes alimentados com ações com diferentes níveis de adição da SL491* à base de própolis.

\begin{tabular}{lcccccccc}
\hline & \multicolumn{9}{c}{ Rendimento (\%) } \\
\cline { 2 - 9 } & Trat1 & Trat2 & Trat3 & Trat4 & Trat5 & Trat6 & $\begin{array}{l}\text { Valor } \\
\text { de P }\end{array}$ & $\begin{array}{l}\text { CV } \\
*(\%)\end{array}$ \\
\hline Filé & 31,14 & 29,04 & 30,75 & 28,83 & 28,51 & 30,98 & 0,581 & 8,99 \\
Pele bruta & 9,94 & 7,78 & 8,70 & 8,24 & 8,93 & 8,29 & 0,729 & 14,34 \\
Pele limpa sem & 3,51 & 3,19 & 3,67 & 3,47 & 3,35 & 3,58 & 0,931 & 21,83 \\
escamas & & & & & & & & \\
\hline
\end{tabular}

*C.V. coeficiente de variação. Fonte: Autores.

\section{Qualidade de resistência dos couros}

Os resultados das análises físico-mecânicas dos couros podem ser verificados nas Tabela 6 e 7. Em relação à espessura do couro, foi observado um aumento significativo para os níveis Trat5 e Trat6 em relação Trat1 (Tabela 6). Fujikura et al. (1998), cita que a espessura da derme é determinada principalmente, pela proporção das fibras colágenas na pele, isso indica que a SL491* promoveu o aumento nessa proporção, devido ao aumento da espessura do couro. O ideal teria sido fazer uma análise histológica da pele, para quantificar as fibras colágenas, análise que infelizmente não foi possível realizar na ocasião do experimento. Não foi observada diferença significativa entre a força máxima de rasgamento e o rasgamento progressivo.

A ração com os diferentes níveis de própolis (produto SL491*) fornecidos para as tilápias, influenciaram na espessura do couro (Tabela 2). Houve um efeito linear positivo sendo explicado pela equação $Y=0,0211 x+0,3203\left(R^{2}=0,844\right)$. Este resultado permite inferir que altas quantidades de própolis na dieta de peixes podem influenciar positivamente na espessura dos couros. Com isso, a justificativa é que a ração com 250g de SL491*/100 kg estimulou o desenvolvimento dos fibroblatos e consequentemente ativou a formação das fibras colágenas. Souza et al. (2021, dados não publicados) avaliaram as características de resistência do couro de coelhos Nova Zelândia Branco alimentados com ração contendo o produto SL491*, à base de própolis. Os autores utilizaram níveis crescentes de própolis de $0 \mathrm{~g}$ a $250 \mathrm{~g} / 100 \mathrm{~kg}$ de ração, conforme o aplicado neste experimento e afirmaram que os níveis do produto SL491* adicionados às rações não apresentaram efeito sobre as características de resistência dos couros. Mas, também mencionaram que houve um efeito linear para a espessura do couro no sentido longitudinal, cuja equação que explicação esse resultado é $\mathrm{Y}=0,0211 \mathrm{x}+0,3203\left(\mathrm{R}^{2}=0,844\right)$.

Quando avaliado os parâmetros da qualidade dos couros quanto a força máxima aplicada no teste e o rasgamento progressivo houve influência do acréscimo do produto SL491* à base de própolis na ração. No entanto, para os parâmetros de força máxima, tração, deformação e alongamento não houve influencia (Tabelas 6 e 7). Apesar de não ter diferido significativamente na resistência dos couros nos diferentes tratamentos, a idade dos peixes ou o tempo de utilização do produto podem ter influenciado nesses resultados. Provavelmente houve necessidade de maior tempo de uso do produto SL491*, para aumentar a espessura das peles e consequentemente influenciar nestes testes de resistência a tração e alongamento, assim como na força aplicada neste teste e a deformação dos couros. Talvez, se fosse realizado uma análise das peles dos peixes alimentados com ração com o uso da própolis (SL491*) em diferentes idades de desenvolvimento atingindo um peso muito superior ao obtido neste experimento, fosse possível encontrar maior variação na espessura e, consequentemente para todos os parâmetros de avaliação da resistência dos couros. 
Tabela 6 - Valores médios das análises de rasgamento progressivo do couro dos peixes alimentados com rações com diferentes níveis de própolis (produto SL491*).

\begin{tabular}{lcccccccc}
\hline Variáveis & \multicolumn{9}{c}{ Rasgamento progressivo } \\
\cline { 2 - 9 } & Trat1 & Trat2 & Trat3 & Trat4 & Trat5 & Trat6 & $\begin{array}{l}\text { Valor } \\
\text { de P }\end{array}$ & CV (\%) \\
\hline Espessura (mm) & 0,352 & 0,370 & 0,376 & 0,377 & 0,423 & 0,468 & $0,0001^{1}$ & 11,51 \\
Força máxima (N) & 14,00 & 14,50 & 15,00 & 15,86 & 16,25 & 18,57 & $0,0001^{2}$ & 20,76 \\
Rasgo (N/mm) & 34,70 & 38,06 & 40,57 & 43,27 & 49,94 & 51,08 & $0,0001^{3}$ & 23,74 \\
\hline
\end{tabular}

Equação linear espessura: $Y=0,0211 x+0,3203\left(R^{2}=0,844\right)$, força máxima $Y=0,8274 x+12,801\left(R^{2}=0,8951\right)$ e rasgo $Y=0,0211 x$ $+0,3203 \mathrm{R}^{2}=0,844$. Fonte: Autores.

Figura 1 - Gráfico e equação de regressão da espessura, força máxima e rasgo dos couros das tilápias alimentadas com ração contendo diferentes níveis de própolis (produto SL491*).

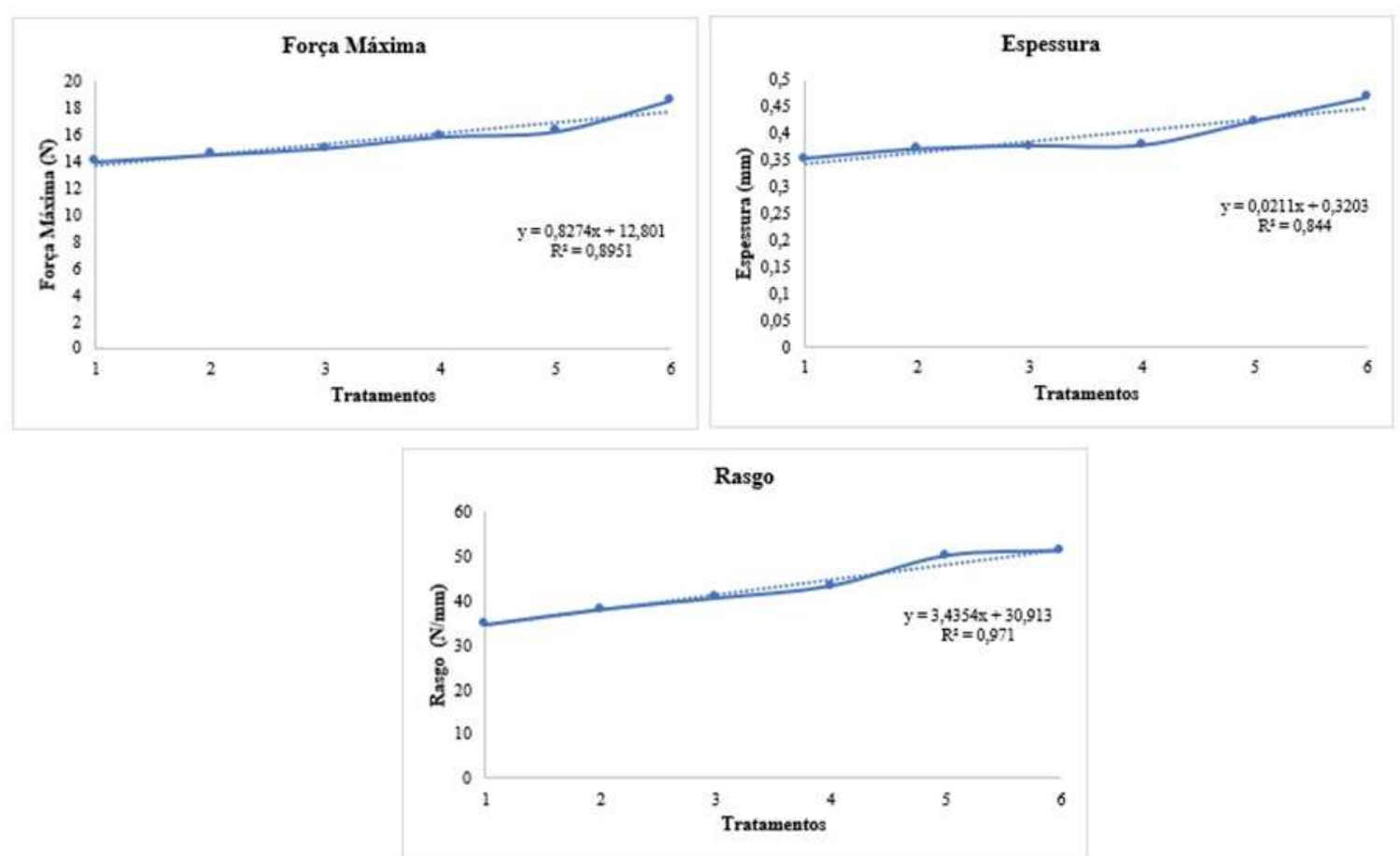

Fonte: Autores.

Com a realização da determinação do rasgamento progressivo, com a força aplicada no teste os corpos de provas vão sendo estirados até o seu rompimento. Na Figura 2, nota-se que alguns corpos de prova se romperam mais, exigindo mais força (N) na realização do teste. Nos Tratamento 3 a Tratamento 5, pode-se verificar que o corpo de prova quase se rompeu e no Trat 6, houve o total rompimento. A força aplicada no Tratamento 3 foi maior $(15 \mathrm{~N})$ comparada a força aplicada no tratamento 1 $(14 \mathrm{~N})$ e consequentemente a do tratamento $6(18,57 \mathrm{~N})$ superior as demais. Com isso os resultados do rasgamento progressivo também aumento linearmente de 34,70 a 51,08 N/mm, cuja equação que explica o ocorrido é $\mathrm{Y}=0,0211 \mathrm{x}+0,3203 \mathrm{R} 2=0,844$. 
Figura 2 - Corpos de prova após a realização do teste de rasgamento progressivo dos couros das tilápias alimentadas com rações com diferentes níveis de adição de própolis (produto SL491*).

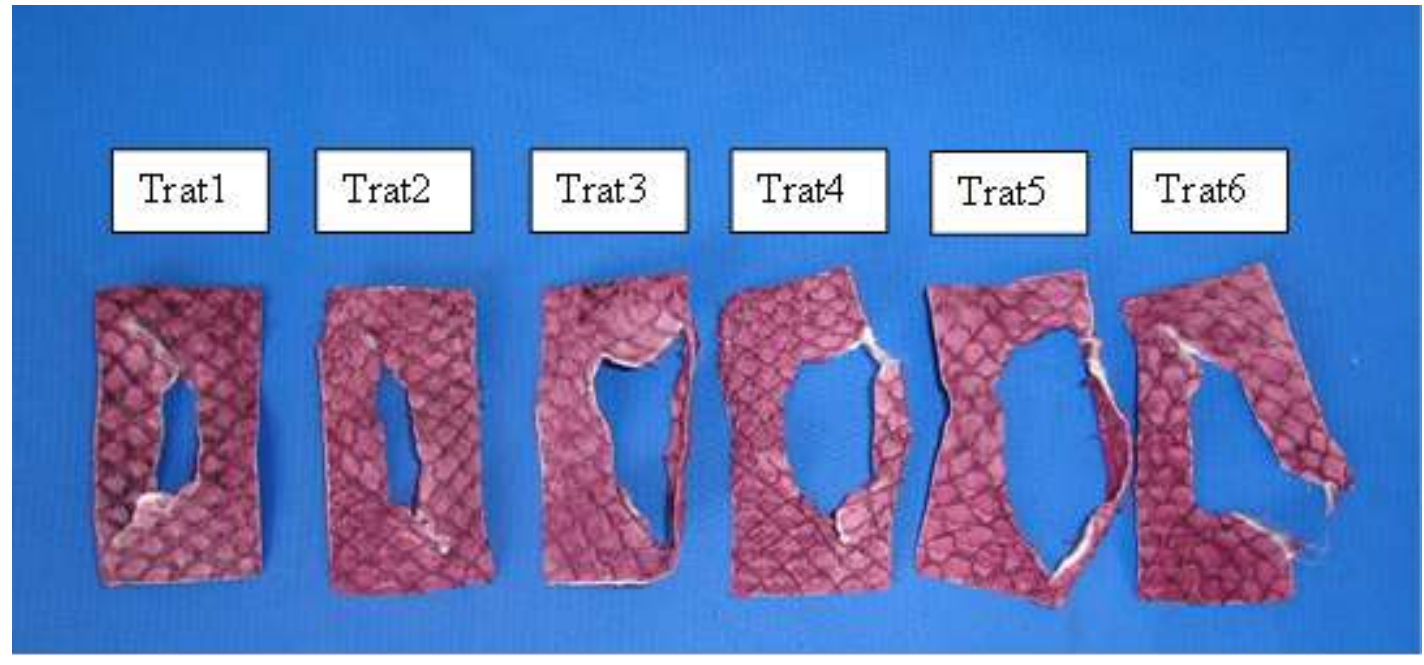

Fonte: Autores (2021).

Tabela 7 - Valores médios das análises de resistência dos couros dos peixes alimentados com rações com diferentes níveis de adição de própolis (produto SL491*).

\begin{tabular}{lcccccccc}
\hline Variáveis (\%) & \multicolumn{9}{c}{ Tração e alongamento } \\
\cline { 2 - 9 } & Trat1 & Trat2 & Trat3 & Trat4 & Trat5 & Trat6 & Valor & CV (\%) \\
& & & & & & & & de P \\
& & & & & & & & \\
\hline Força máxima (N) & 55,14 & 50,00 & 65,62 & 69,75 & 58,43 & 56,60 & 0,527 & 22,50 \\
Tração (N/mm $\left.{ }^{2}\right)$ & 17,69 & 16,94 & 20,02 & 20,91 & 14,96 & 14,44 & 0,831 & 15,84 \\
Deformação (mm) & 37,43 & 31,57 & 36,87 & 37,25 & 36,14 & 42,80 & 0,642 & 10,40 \\
Alongamento (\%) & 62,43 & 52,86 & 61,50 & 60,14 & 62,37 & 71,00 & 0,829 & 10,39 \\
\hline
\end{tabular}

Fonte: Autores.

Para melhor entender os resultados da Tabela 7, pode-se observar a Figura 3 onde constam uma repetição (corpos de provas) de cada tratamento. Para a determinação da tração e alongamento dos corpos de prova, a força máxima aplicada no teste vai proporcionar o estiramento do corpo de prova até o seu rompimento. Sendo assim, pode-se determinar a força necessária para o alongamento e o quanto foi necessário tracionou para a ruptura do couro. 
Figura 3 - Corpos de prova após a realização do teste de tração e alongamento dos couros das tilápias alimentadas com rações com diferentes níveis de adição de própolis (produto SL491*).

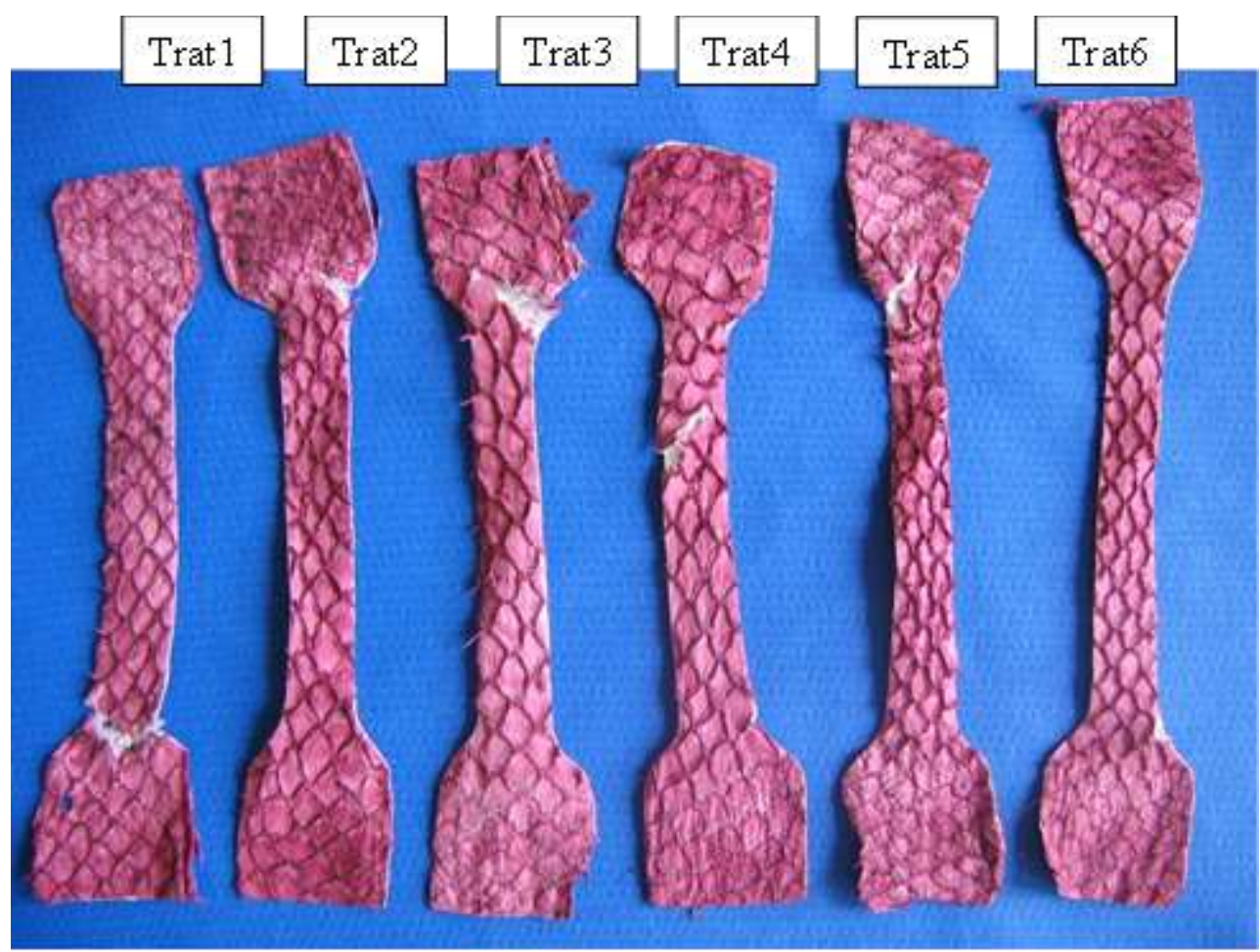

Fonte: Autores (2021).

De acordo com Souza et al. (2021), o princípio da resistência à tração baseia-se nessa determinação da força necessária para romper o material e seu alongamento percentual (no ponto de ruptura e por carga específica). Neste experimente, nota-se que houve uma variação entre os corpos de provas, quanto ao seu comprimento, ruptura em tamanho e posição diferenciada no rompimento, e pela análise estatística realizada mostra que não houve diferença significativa, essa variação observada nesses corpos de provas foi pequena.

\section{Conclusão}

A adição de SL491* à base de própolis promoveu um efeito positivo no peso dos peixes, no ganho de peso médio, no entanto não interferiu na conversão alimentar. Porém o mais indicado seria incluir até $200 \mathrm{~g} / 100 \mathrm{~kg}$ de ração, pois acima disso mostrou-se uma redução de peso e ganho de peso dos animais. O rendimento médio de filé, de pele bruta e pele limpa sem escamas, não foram influenciados pela adição de SL491*. Quando avaliado os parâmetros da qualidade dos couros, a espessura, a força máxima aplicada no teste e o rasgamento progressivo aumentaram com o acréscimo do produto SL491* à base de própolis na ração. Já não houve influência da adição de SL491* à base de própolis na ração quanto aos parâmetros de força máxima aplicada na determinação da tração e alongamento, para a elasticidade (alongamento), para a resistência a tração e a deformação específica até a ruptura do couro. Contudo, são necessários mais estudos para se verificar a influência da própolis (SL491*) no desempenho e qualidade dos couros de peixes.

\section{Referências}

ABNT. (2021). NBR 10455: 2021 climatização de materiais usados na fabricação de calçados e correlatos. Associação Brasileira De Normas Técnicas -ABNT. p. 2

ABNT. (2014). NBR ISO 3376: 2014 couro -Ensaios físicos e mecânicos -determinação da força de rasgamento progressivo. Parte 1: rasgamento de extremidade simples. Associação Brasileira De Normas Técnicas -ABNT. p. 4 
ABNT. (2014). NBR. 3377-7. Couro — Ensaios físicos e mecânicos — Determinação da força de rasgamento. (ABNT)

ABNT. (2020). NBR.11114. Couro. Determinação da medida de resistência a flexões contínuas. Normas Técnicas (ABNT

Adeodato, S. Peles Exóticas e Ecológicas (1995). Globo Ciência, 51, 56-60.

Andriguetto, J.M.; Perly, L.; Minardi, I. et al. (1989). Nutrição Animal. (3a ed.),1, 395p.

Bankova, V., Dyulgerov, A., Popov, S., Evstatieva, L., Kuleva, L., Pureb, O., \& Zamjansan, Z. (1992). Propolis produced in Bulgaria and Mongolia: phenolic compounds and plant origin. Apidologie, 23(1), 79-85.

Bankova, V., Kujumgiev, A., Ignatova, A. et al. (1989). Antibacterial activity of Bulgarian and Mongolian propolis and poplar buds. In: Proc Vth Int. Conference Chem. Biotechnol Biol. Active Nat. Prod., V.2, Vana: Bulgaria. Proceedings, 239-243.

Barroso, R. M., Pincinato, R. B. M., \& Munoz, A. E. P. (2017). O mercado da tilápia-2 trimestre de 2017 e Análise da estrutura do preço da tilápia no varejo. Embrapa Pesca Aquic. Newsletter, 1-19.

Bianchini, L., \& Bedendo, I. P. (1998). Efeito antibiótico da própolis sobre bactérias fitopatogênicas. Scientia agricola, 55, $149-152$.

Biavatti, M. W., Bellaver, M. H., Volpato, L., Costa, C., \& Bellaver, C. (2003). Preliminary studies of alternative feed additives for broilers: Alternanthera brasiliana extract, propolis extract and linseed oil. Brazilian Journal of Poultry Science, 5, 147-151.

Burdock, G. A. (1998). Review of the biological properties and toxicity of bee propolis (propolis). Food and Chemical toxicology, 36(4), 347-363.

Cabral, I. S. R., Oldoni, T. L. C., Prado, A., Bezerra, R. M. N., Alencar, S. M. D., Ikegaki, M., \& Rosalen, P. L. (2009). Composição fenólica, atividade antibacteriana e antioxidante da própolis vermelha brasileira. Química Nova, 32, 1523-1527.

Carvalho, G. G. P. D., Pires, A. J. V., Veloso, C. M., Silva, F. F. D., \& Carvalho, B. M. A. D. (2006). Silagem de resíduo de peixes em dietas para alevinos de tilápia-do-nilo. Revista Brasileira de Zootecnia, 35, 126-130.

Castaldo, S., \& Capasso, F. (2002). Própolis, um antigo remédio usado na medicina moderna. Fitoterapia, 73, S1-S6.

Garcia-Viguera, C., Greenaway, W., \& Whatley, F. R. (1992). Composition of propolis from two different Spanish regions. Zeitschrift für Naturforschung C, 47(7-8), 634-637.

Grange, J. M., \& Davey, R. W. (1990). Antibacterial properties of propolis (bee glue). Journal of the Royal Society of Medicine, 83(3), 159-160.

Grassi, T. L. M. (2014). Qualidade de filés de tilápia alimentadas com pigmentante de origem bacteriana.Dissertação apresentada à Faculdade de Medicina Veterinária de Araçatuba - Unesp.

Greenaway, W., May, J., Scaysbrook, T., \& Whatley, F. R. (1991). Identification by gas chromatography-mass spectrometry of 150 compounds in propolis. Zeitschrift für Naturforschung C, 46(1-2), 111-121.

Greenaway, W., Scaysbrook, T., \& Whatley, FR (1987). Análise do exsudato de gemas de Populus x euramericana, e de própolis, por cromatografia gasosaespectrometria de massa. Proceedings of the Royal Society of London. Series B. Biological sciences, 232 (1268), $249-272$.

Hayashi, C., Boscolo, W. R., Soares, C. M., Boscolo, V. R., \& Galdioli, E. M. (1999). Uso de diferentes graus de moagem dos ingredientes em dietas para a tilápia-do-Nilo (Oreochromis niloticus L.) na fase de crescimento. Acta Scientiarum. Animal Sciences, 21, $733-737$.

Hoinacki, E. \& Gutheil N. C. (1989). Peles e couros: origens, defeitos e industrialização. (2a ed.), CEP SENAI de Artes Gráficas, 320 p.

Hoinacki, E., Moreira, M. V., \& Kiefer, C. G. (1994). Manual básico de processamento do couro (pp. 356-364). SENAI.

Jacinto, M., \& Ferrari, W. (1992). Pele de peixe: uma matéria-prima abundante e inesgotável. Rev. do couro, 18, 30-31.

Koltuksuz, U., Özen, S., Uz, E., Aydinç, M., Karaman, A., Gültek, A., \& Aydin, E. (1999). O éster fenetílico do ácido caféico evita lesões de reperfusão intestinal em ratos. Journal of Pediatric Surgery, 34 (10), 1458-1462

Koo, H., Gomes, B. P. F. A., Rosalen, P. L., Ambrosano, G. M. B., Park, Y. K., \& Cury, J. A. (2000). Atividade antimicrobiana in vitro da própolis e Arnica montana contra patógenos orais. Arquivos de biologia oral, 45 (2), 141-148.

Kubitza, F. (2000). Tilápia: Um bom planejamento gera alta rentabilidade. Panorama da aquicultura. (10)52,44-53.

Kujumgiev, A., Tsvetkova, I., Serkedjieva, Y., Bankova, V., Christov, R., \& Popov, S. (1999). Atividade antibacteriana, antifúngica e antiviral de própolis de diferentes origens geográficas. Journal of ethnopharmacology, 64 (3), 235-240.

Larezzi, A. (1988). Peles de peixes: matéria-prima para confecções, calçados e acessórios de moda. Setor Couro, 19, 8-9.

Magro Filho, O., \& De Carvalho, A. C. P. (1990). Aplicação de própolis em cavidades dentais e feridas cutâneas. The Journal of Nihon University School of Dentistry, $32(1), 4-13$.

Marcucci Torres, M. L., Pessine Novaes de Lima, B., Marcucci, M. C., \& Negrão, V. (2021). Uso de pomada de própolis brasileira tipificada e dimetilsulfóxido para tratamento de feridas cirúrgicas. Brazilian Journal of Natural Sciences, 4(2).

Marcucci, M. C. (1995). Própolis: composição química, propriedades biológicas e atividade terapêutica. Apidologie, 26 (2), 83 -99. 
Markham, K. R., Mitchell, K. A., Wilkins, A. L., Daldy, J. A., \& Lu, Y. (1996). Identificação por HPLC e GC-MS dos principais constituintes orgânicos da própolis da Nova Zelândia. Phytochemistry, 42 (1), 205-211.

Matiucci, M. A., Alemida, G. C.A., da Silva, J. M., de Cássia Spacki, K., Chambo, A. P. S., Araujo, E. S., \& Vieira, A. M. S. (2020a). Aproveitamento e valorização de resíduos na filetagem de tilápia. Editora Atena. 1-388.

Mazzuco, H., Silva, R. D. M., Berchieri Jr, A., \& Oliveira, E. D. (1996). Utilização da própolis e álcool etílico no controle de Salmonella em rações avícolas. Scientia agricola, 53(1).

Moreira, R. T., de Oliveira, B. S., \& da Rocha, A. A. (2018). Própolis: Uma Alternativa No Tratamento De Feridas Cirúrgicas Em Bovinos. Revista Eixo, 7(1), 3-9.

Moreno, M. N., Isla, M. I., Cudmani, N. G., Vattuone, M. A., \& Sampietro, A. R. (1999). Screening of antibacterial activity of Amaicha del Valle (Tucumán, Argentina) propolis. Journal of ethnopharmacology, 68(1-3), 97-102.

Moura, L. P. P., Scapinello, C., Martins, E. N., Franco, S. L., \& Ribeiro, M. C. M. (1998). Efeito da solução hidroalcoólica de própolis e robenidina sobre a contagem de oocistos por grama de fezes de Eimeria spp. em coelhos Nova Zelândia Branco. Rev. Bras. Zootec, 325-330.

Orhan, H., Marol, S., Hepsen, I. F., Sahin, G., (1999). Effects of some probable antioxidants on selenite-induced cataract formation and oxidative stress-related parameters in rats. Toxicology, 139, 213-232.

Paixão, D. R., Flausino, P. A., Reis, N. G., de Lima, C. C., Bernardes, M. T. C. P., Santos, L., \& Garcia, J. A. D. (2014). Efeitos da própolis na proliferação de fibroblastos em lesões cutâneas de ratos. Revista de Ciências Farmacêuticas Básica e Aplicada, 35(3).

Peixe BR. Associação Brasileira de Piscicultura. Anuário Peixe BR da Piscicultura (2021). São Paulo: Peixe BR, 2 Peixe BR. Associação Brasileira de Piscicultura. Anuário Peixe BR da Piscicultura 2021. Peixe BR.

Pereira, A. C.; Silva, R. F. (2012). Produção de tilápias. Niterói: Rio Rural, (Manual técnico 31). http://www.microbacias.rj.gov.br/ conteudo/compartilhados/pesquisa_participativa_apoio_tecnico/31\%20\%20Produ\%C3\%A7\%C3\%A30\%20de\%20Til\%C3\%A1pias.pdf.

Pereira, A. D. S., Seixas, F. R. M. S., \& Aquino Neto, F. R. D. (2002). Própolis: 100 anos de pesquisa e suas perspectivas futuras. Química Nova, 25(2), 321326.

Rijkers, G. T., Van Oosterom, R., \& Van Muiswinkel, W. B. (1981). The immune system of cyprinid fish. Oxytetracycline and the regulation of humoral immunity in carp (Cyprinus carpio). Veterinary immunology and immunopathology, 2(3), 281-290.

Rivera, N. L. M., Risolia, L. W., Sabchuk, T. T., Félix, A. P., Maiorka, A., \& Scapinello, C. (2019). Digestibilidade e palatabilidade de dietas com extrato de própolis para cães. Ciência Animal Brasileira, 20.

Santos, A. V. D., Teixeira, A. S., Rodrigues, P. B., Freitas, R. T. F. D., Guimarães, A. M., \& Giacometti, R. A. (2003). Valor nutritivo do resíduo de própolis para frangos de corte. Ciência e Agrotecnologia, 27, 1152-1159.

Santos, E. L., da Silva, F. C. B., da Conceição Pontes, E., Lira, R. C., \& Cavalcanti, M. C. A. (2013). Resíduo do processamento do extrato de própolis vermelha em ração comercial para alevinos de tilápia do Nilo (Oreochromis niloticus). Comunicata Scientiae, 4(2), 179-185.

SAS Institute Inc., (2010). The data analysis for this paper was generated using SAS/STAT software, Version 9.3 of the SAS System for Windows. Copyright $\odot$ 2010 SAS Institute Inc. SAS and all other SAS Institute Inc. product or service names are registered trademarks or trademarks of SAS Institute Inc., Cary, NC, USA

Silva, F. V., Sarmento, N. L. D. A. F., Vieira, J. S., Tessitore, A. J. D. A., Oliveira, L. L. D. S., \& Saraiva, E. P. (2009). Características morfométricas, rendimentos de carcaça, filé, vísceras e resíduos em tilápias-do-nilo em diferentes faixas de peso. Revista Brasileira de Zootecnia, 38, 1407-1412.

Silva, L. E., \& Galício, G. (2012). Alimentação De Peixes Em Piscicultura Intensiva. Enciclopédia Biosfera, 8(15).

Silva, R. E. (2016). Perfil da piscicultura dos médios e grandes produtores do município de Matinha-Maranhão. TCC de Graduação do Curso de Agronomia do Campus de Chapadinha.

Souza, M. L. R. D. (2002). Comparação de seis métodos de filetagem, em relação ao rendimento de filé e de subprodutos do processamento da Tilápia-do-Nilo (Oreochromis niloticus). Revista Brasileira de Zootecnia, 31, 1076-1084.

Souza, M. L. R., Cucatti, T., Andrade, M. B., Godoy, L. C., Tozzi, M. A. C., Cavallieri, R. F., \& Silva, L. O. (2004). Diferentes técnicas de recurtimento em peles de tilápia-do-Nilo (Oreochromis niloticus): qualidade de resistência. Ensaios Cienc, 8(2), 195-202.

Tiveron, A. P. (2015). Caracterização e identificação de compostos com atividade antioxidante de própolis orgânica brasileira Doctoral dissertation, Universidade de São Paulo).

Vanhaelen, M., \& Vanhaelen-fastri, R., (1979(a). Própolis-I. Origine micrographie, composition, Chinique el activit-therapeutique. J. Pharm. Belg., 34, 253259, 1979(a).

Vanhaelen, M., \& Vanhaelen-Fastri, R., (1979(b) Própolis II. Identification par chromatographies haute-performance (liquide, eq-liquide et sur couches minces) _eq constituants. Bioautographie_eq chromatogrammes_eq composés antibactériens. J Pharm Belg., 34, 317-328. 